\title{
VENTAJAS E INCONVENIENTES DE LA PARTICIPACIÓN DE IA AUDIENCIA EN LOS PROGRAMAS DE RADIO
}

\author{
Susana Herrera Damas \\ Profesora en la facultad de Comunicación de la Universidad De Piura (Perú)
}

Resumen

Desde los años cuarenta, la participación de los oyentes en los programas de radio ha sido la fórmula participativa que más se ha desarrollado, diversificado y consolidado. No obstante, pese a su versatilidad para las programaciones radiofónicas, lo cierto es que, como cualquier otro elemento programático, esta fórmula tiene también algunos inconvenientes. El presente artículo describe el sentido y contrasentido del empleo de esta fórmula y demanda para el futuro una mayor mediación profesional por parte de quienes realizan los programas, no sólo en la última parte del proceso comunicativo sino desde el mismo diseño y configuración de las programaciones.

Palabras clave

Participación de audiencia, programas de participación, radio.

\section{Abstract}

Since the forties, listener participation on radio programs has been the most widely developed, diversified and consolidated participative formula. Despite its easiness for radio programs, the certain fact is that, as any other program element, the formula do have its inconveniences. The present paper describes both sense and countersense of the formula use, as well as the future demand of a more professional exercise on those who manage programs, not only regarding the end of the communication process, but in the design itself and configuration of programs.

Key words

Audience participation, phone in programs, radio. 


\section{INTRODUCCIÓN}

La participación directa de los oyentes en los programas de radio se define como aquella fórmula participativa posibilitada por los profesionales de los medios que, mediante la disposición de cauces convencionales y a través de un ejercicio de mediación profesional llevado a cabo en la última etapa del proceso comunicativo, facilita un contacto e intercambio profesional entre los roles de emisor y receptor y hace posible que los oyentes intervengan en el contenido de las emisiones.

En la actualidad, se trata de la fórmula participativa más frecuente y constituye un elemento puesto a disposición de profesionales y oyentes, que puede ser utilizado por unos y otros con gran variedad de fines y propósitos. En virtud de este carácter instrumental, el uso de las llamadas de los oyentes en los programas de radio entraña una serie de ventajas y de inconvenientes. Este artículo pretende precisamente revelar la naturaleza de unos y otros.

La información que aquí se describe es el resultado de una valoración propia realizada a partir de la bibliografía existente sobre el tema así como de las consideraciones aportadas por profesionales de las cuatro cadenas generalistas españolas con los que se mantuvo entrevistas durante los meses de junio y julio de 2000 en Madrid y Barcelona'. En todos los casos, la realización de las entrevistas partió de un cuestionario semi-estructurado que resultó de gran utilidad para guiar la conversación y para obtener otras valoraciones complementarias.

Además, al ser la participación directa de los oyentes una fórmula plenamente consolidada en diferentes sistemas radiodifusores (Merayo, 2000: 213), las observaciones y valoraciones académicas sobre el particular han servido también para completar algunas de las afirmaciones aquí expuestas. Lógicamente, esta consideración se encuentra sujeta a aquellas modalidades participativas que presentan alguna similitud con las que se observan en la programación de la radio española².

\section{VENTAJAS DE LA PARTICIPACIÓN DIRECTA DE LA AUDIENCIA}

La participación directa de la audiencia en los programas de radio ofrece ventajas para el emisor y para el receptor. Para la emisora, algunas de estas ventajas son de tipo económico y otras

\footnotetext{
La selección de los entrevistados se hizo en función de su presencia en programas que incluyesen determinadas modalidades de participación. Se procuró que la mayor parte de las modalidades descritas en el epígrafe anterior estuvieran representadas, razón por la que se mantuvo entrevistas con responsables de la programación de cada una de las cuatro cadenas generalistas. En concreto, se mantuvo entrevistas con: en RNE, José María de Juana, José Antonio García, Javier Capitán, Julio César Iglesias, Basilio Rogado, Nieves Herrero, Ignacio Elguero, Manuel Antonio Rico, Pilar Socorro y Ana Ramos; en la Cadena SER, con Genma Nierga, Fina Rodríguez y Roberto Sánchez; en Onda Cero, con Marta Robles, Carlos Pumares, Eduardo García y Juan Antonio Cebrián y en la Cadena COPE, con Matías Antolín, María José Navarro, María José Bosch, Sonsoles Gállego y Miguel Chiwerto.

2 Este trabajo parte de la consideración de una tipología propia, a partir de cinco criterios. En el presente artículo, se menciona sólo uno de los criterios, el de finalidad de las intervenciones porque es el que guarda mayor relación con las ventajas e inconvenientes de la participación de los oyentes en los programas de radio. En concreto, según este criterio, cabe distinguir un total de nueve modalidades participativas, según los oyentes se dirijan a la radio para: 1) expresar una opinión, 2) rectificar una información, 3) aportar información, 4) relatar un caso propio o ajeno, 5) consultar una información, 6) denunciar un hecho o situación, 7) desahogarse, 8) pedir información u opinión y 9) concursar. Para un conocimiento más detallado de la presente tipología puede verse, Herrera, $2002: 31$ 1-346.
} 
tienen un carácter más intangible y se refieren a la imagen que la citada emisora desea transmitir. Por su parte, el oyente que se dirija a la radio para intervenir en uno de sus programas puede obtener también algunas compensaciones, referidas en su mayor parte a la satisfacción de sus necesidades comunicativas. Además, en ciertos casos, esta satisfacción puede ir acompañada de una gratificación más concreta, a través, por ejemplo, de la resolución de alguna demanda. Tal vez en el ajuste tan estrecho entre las necesidades de la audiencia y de los profesionales se encuentre una de las claves del éxito y de la popularidad creciente del uso de esta fórmula en la actual programación radiofónica.

\section{PERMITE SATISFACER LAS NECESIDADES COMUNICATIVAS DE LA AUDIENCIA}

En primer lugar, la participación directa de los oyentes en los programas de radio permite a estos satisfacer sus necesidades comunicativas, ya que pone a su disposición un acceso rápido, cómodo y sencillo, que, en ocasiones, se encuentra sólo restringido al juicio del productor y a las posibles limitaciones técnicas de falta de tiempo y de bloqueo de las líneas telefónicas del programa.

Se trata de una necesidad plenamente humana, que la radio -tal vez como ningún otro medio- es capaz de satisfacer, debido a sus mismas características. Este hecho no ha pasado desapercibido para los oyentes, que valoran la sensación de proximidad y de empatía psicológica que posibilita el medio, al que agradecen la posibilidad de "permitirnos hablar". En otras ocasiones, esta sensación de proximidad se ve reforzada con el sentimiento de familiaridad que el oyente llega a establecer con el presentador o con alguno de los colaboradores del programa ${ }^{3}$.

Esta ventaja resulta de gran utilidad cuando los oyentes se dirigen a la radio con la intención de desahogarse públicamente. Frente a las acusaciones de sensacionalismo con las que en alguna ocasión se ha descalificado a estos programas, también se ha afirmado que éstos posibilitan una ocasión de comunicación a gente que tradicionalmente no tiene la posibilidad de acceder a otros cauces de expresión (Muñoz y Gil, 1986: 133).

Los responsables de estas emisiones han destacado también la oportunidad que ofrecen estos espacios para expresarse públicamente. Así, según Nierga, el éxito del programa "Hablar por hablar", puede ser atribuido a las "ganas y la necesidad de hablar" de la gente (Nierga, 1996: 17) mientras que el perfil del programa está compuesto sobre todo por "personas que no hablan mucho con quien tienen que hablar. Tienen en común graves problemas personales y, los que ayudan, ganas de ayudar. Hay gente joven, estudiante, gente mayor... no hay un perfil, sólo la necesidad de hablar" (Nierga, 2000).

\footnotetext{
3 Las expresiones de "Os escucho todos los días y os felicito por el programa porque me lo hacéis pasar muy bien", o "gracias por hacernos un hueco", así como las referencias a determinados integrantes del programa se han convertido en prácticas habituales en el inicio de las intervenciones de numerosos oyentes que se dirigen a los programas
} 
Además, esta ventaja puede resultar de gran utilidad cuando el oyente se dirige a la radio para denunciar un hecho o a expresar una opinión, sobre todo en aquellos casos en los que el oyente desea expresar una opinión que considera silenciada en el discurso de los contertulios (Lalinde, 1998: 57).

En el sentido descrito, cabe afirmar que "con todas sus limitaciones, la participación radiofónica tiene el indiscutible mérito de actualizar cotidianamente el derecho a la libertad de expresión" (Merayo, 2000: 218). Además, esta ventaja está relacionada con los componentes de instrumentalidad y de expresividad en la participación radiofónica de la audiencia. El componente de expresividad -la autoafirmación de la propia identidad o la pertenencia a una clase, grupo o colectivo al que normalmente se considera perjudicado- se antepone al componente instrumental -la consecución de un determinado fin-. Así, en ocasiones, el oyente puede ser consciente de que el medio no puede resolver su problema pero, aun así, se conforma con la oportunidad que le ofrece un determinado programa para expresar una opinión personal o para denunciar una situación con la que no está de acuerdo.

\section{AMPLÍA LA ESFERA PÚBLICA}

Además, la participación directa de la audiencia se revela como una eficaz fórmula con la que intensificar la esfera pública a partir de la expresión de puntos de vista diferentes o del conocimiento de casos propios.

Se parte en este punto de la redefinición del concepto de esfera pública según lo apuntado por Keane que considera que, en la actualidad, este concepto no estaría ya conformado por un espacio homogéneo y uniforme sino que pasaría a estar integrado por una amplia multiplicidad de pequeñas esferas públicas de diverso tamaño, que se "traslapan e interconectan" (Keane, 1997: 56).

En una posible traducción de este concepto a términos de programación radiofónica, este complejo mosaico de pequeñas esferas públicas interconectadas podría remitir a otras nociones como las de pluralismo y multiplicidad de actores. En efecto, el pluralismo en las emisiones y programaciones ha sido tradicionalmente una de las principales preocupaciones en las diferentes legislaciones que ordenan la radiodifusión pública. Conscientes de esta preocupación, algunos legisladores han previsto ciertos mecanismos -ley de acceso, representación del público en órganos de gestión o control, etc.- con los que se intenta incrementar el citado pluralismo. El caso español tampoco ha sido ajeno a este tipo de normativas aunque su aprobación legal no siempre ha coincidido con una puesta en práctica suficiente y eficaz. De esta forma, a la espera de aplicar estas otras fórmulas, la participación directa de los oyentes en los programas de radio podría servir como otro medio o remedio de retroacción con el público, viniendo a suplir en parte las deficiencias mencionadas. 
Es evidente que esta fórmula resulta insuficiente para resolver todas las carencias e insuficiencias de forma que, por sí misma, la incorporación en antena de las voces de los oyentes pudiera garantizar la satisfacción del pluralismo social deseable en las emisiones. Una misión de este tipo resultaría excesivamente pretenciosa para esta fórmula. Sin embargo, por otra parte, reconocer este hecho no invalida la capacidad de la participación directa de los oyentes para servir de fuente complementaria con la que tratar de garantizar ese mayor pluralismo en cuanto al acceso de los ciudadanos a los medios de comunicación, ampliando así el espectro de intervenciones $y$, por ende, intensificando la esfera pública.

En este contexto y en particular referencia a la radio pública, la incorporación en antena de los oyentes podría suponer una realización efectiva de la función orientada al "servicio público", ejerciendo un cierto efecto corrector de las insuficiencias que se detectan en la aplicación del derecho de antena, teóricamente contemplado en las disposiciones legales vigentes. Por su parte, la radio comercial -aunque ajena en este punto a lo dispuesto en la legislación vigente- suele destacar la oferta de una programación plural, atenta a lo que sus oyentes tienen que decir, como uno de sus elementos promocionales.

Es cierto que, al realizarse dentro de las condiciones del lenguaje radiofónico, la participación de la audiencia se encuentra con límites evidentes de tipo técnico y de falta de tiempo para dar cabida a todas las llamadas que solicitan intervenir en el programa (Winocur, 2000: 44). A pesar de estos límites, también se ha destacado la capacidad de la radio para poner en escena en antena, en este caso- determinadas inquietudes y preocupaciones de algunos sectores del público que, de otra forma, se encontrarían con mayores obstáculos para acceder a los medios. De esta manera, estos espacios constituirían una alternativa válida como foro de presión y de expresión de las necesidades de la ciudadanía. Al mismo tiempo, la radio permite mediar frente a las autoridades, una realidad que tampoco ha pasado desapercibida para los mismos ciudadanos (Winocur, 2000: 44-45).

En concreto, esta ventaja se hace particularmente presente en aquellas modalidades que tienen por objeto expresar una opinión, aportar información, rectificar una información $u$ opinión, pedir información u opinión o denunciar un hecho o situación. En estos casos, las intervenciones de los oyentes pueden contribuir a "enriquecer el programa con visiones casi siempre muy directas de la realidad". En este sentido, Manuel Antonio Rico, director y presentador del programa "24 horas", recordó que "nosotros hablamos de cosas que conocemos pero en las que no estamos metidos" (Rico, 2000).

No obstante, también cabe advertir una ampliación de la esfera pública en las llamadas en las que los oyentes pretenden consultar una información u opinión o desahogarse. En concreto, Mcleish ha señalado que el uso de las opiniones de integrantes "ordinarios" del público añade una dimensión útil a la cobertura de un tema que, de otra forma, quedaría limitado al informe directo de un boletín o a una conversación en el estudio entre funcionarios o expertos: "Cuando se utiliza adecuadamente, la vox pop representa otro color en la paleta de la emisora. Facilita un contraste 
con el material del estudio, y al reflejar con exactitud lo que dice la gente, ayuda al oyente a identificarse con la emisora, con lo que aumenta su credibilidad" (McLeish, 1985: 159).

Las demandas que efectúen los oyentes pueden contribuir también a la configuración de ese tejido de la nueva esfera pública incrementando con sus mensajes ese "complejo mosaico de pequeñas esferas públicas interconectadas". Además, la realización de esta ventaja resulta totalmente acorde con la misma naturaleza mediática de la radio, orientada hacia la difusión de comunicaciones públicas y no privadas (Merayo, 2000: 217).

\section{PERMITE RESOLVER INQUIETUDES CONCRETAS DE LOS OYENTES}

La radio dispone de un enorme potencial para facilitar la participación de los oyentes. En virtud de su sencillez, comodidad y "transparencia" técnicas, el medio posee una gran capacidad para responder a las consultas del público de forma rápida y eficaz. Lógicamente, esta ventaja está supeditada a la autoridad y a la competencia comunicativa del conductor o del experto que responda a las consultas. Aun así, en comparación con el resto de medios, la radio cuenta con las ventajas de la rapidez e inmediatez a la hora de orientar las posibles inquietudes de los oyentes.

La realización plena de esta ventaja se encuentra en el consultorio, que permite una alternancia sucesiva de las preguntas de los oyentes y las respuestas de los expertos. Las intervenciones de la audiencia permiten incluir nuevos contenidos a partir del conocimiento de casos concretos. De esta forma, la casuística se ve favorecida con la exposición de nuevas vivencias reales, lo cual fomenta a su vez la ventaja anterior. Además, el hecho de que los oyentes puedan obtener una respuesta rápida a sus demandas refuerza la credibilidad y la complicidad con el medio tanto para el oyente individual como, por extensión, para el resto de la audiencia.

Esta ventaja se encuentra también presente en el interrogatorio de la audiencia, una modalidad en la que el oyente se dirige al medio para pedir información u opinión sobre algún aspecto que sea de su interés. Para algunos profesionales, esto permite contar con una mayor variedad de puntos de vista, enfoques y perspectivas: "Como periodista no puedes preparar todos los temas en profundidad. Por ejemplo, al llevar a Miguel Guzmán, número 1 en matemáticas, serían más interesantes las preguntas de alguien que conozca la materia. Yo puedo preparar entrevistas, pero no estudiar una carrera. El punto de vista del público es más interesante porque no se limita a las cinco uves dobles" (Socorro, 2000).

También en este caso, el hecho de que el oyente pueda obtener una respuesta rápida a propósito, por ejemplo, de cómo conseguir un libro escrito por la persona a la que se dirige la consulta, o sobre la agenda de conciertos de su grupo de música preferido, puede reforzar la credibilidad de que goza el medio y fomentar el afán de servicio que frecuentemente se le atribuye. 


\section{OFRECE UN RETRATO MÁS PRECISO DE LA AUDIENCIA}

Además, al permitir la realización efectiva de un cierto grado de feedback o retroalimentación en la comunicación radiofónica, los profesionales del medio disponen de un mecanismo más para confrontar el grado de receptividad de sus mensajes. De esta forma, la participación directa de los oyentes en los programas de radio puede servir de instrumento complementario a las diferentes herramientas con que cuentan las emisoras para conocer a la audiencia a la que se dirigen (datos de medición de audiencias, informes sociológicos, estudios e informes propios, comentarios de la gente cuando salen a hacer el programa de cara al público, etc.). De hecho, esta fórmula puede resultar muy útil tanto para conocer cuantitativamente al público que escucha una emisión como para conocer sus aspectos cualitativos (gustos, preferencias, intereses, inquietudes, etc.).

Así, la participación directa de la audiencia podría venir a suplir ciertas carencias observadas a través del empleo en exclusiva de algunas técnicas de investigación -medición- de audiencia como las utilizadas para la elaboración del Estudio General de Medios. A este respecto, Socorro afirmó, por ejemplo que, "el EGM no recoge muchos datos: pueblos pequeños, lugares extranjeros... En el caso de RNE no es siempre fiable porque además el EGM es para dar datos a los publicistas y Radio Nacional de España no es una radio comercial" (Socorro, 2000). Asimismo, más allá de lo puramente cuantitativo, la incorporación en los programas de las intervenciones de los oyentes puede proporcionar una abundante fuente de información acerca de las cuestiones que más interesan a partir del incremento en el volumen de llamadas. A su vez, el conocimiento de las preferencias e inquietudes de la audiencia podría servir para seleccionar nuevos temas, enfoques y perspectivas.

Con todo, algunos profesionales se mostraron escépticos respecto a la validez de este recurso a la hora de obtener un perfil más preciso del público del programa. En la mayor parte de los casos, los profesionales manifestaron que los que llaman no tienen la suficiente representatividad para reproducir la totalidad del público que escucha el programa. Para lgnacio Elguero, subdirector del programa "Lo que es la vida", "la representatividad es dudosa. En un programa de un millón de oyentes, recibes como muchas mil llamadas. Es una representatividad mínima: la inmensa mayoría nunca ha llamado a la radio. Es la representatividad de los que llaman, no de los que escuchan" (Elguero, 2000).

Es obvio que no toda la audiencia que escucha el programa dispone de voluntad, de tiempo 0 , sencillamente, siente la necesidad de dirigirse directamente a la emisora. Así se desprende, en efecto, de buena parte de las intervenciones cuyo comienzo sigue más o menos la siguiente fórmula: "Os escucho todos los días/tardes/noches pero hoy es la primera vez que llamo porque me he sentido particularmente afectada/o impresionada/o identificada/o por...". No obstante, sin ánimo de encontrar una posible representatividad estadística y, a la espera de una utilización más sistemática de técnicas cualitativas para conocer a la audiencia, la escucha de las intervenciones podría guiar la selección de los asuntos que podrían abordarse en posteriores emisiones. Para Pilar Socorro, las intervenciones de la audiencia en el programa tienen una gran utilidad: "Ahí co- 
nozco los temas que tengo que tratar" (Socorro, 2000). En términos similares se expresó Matías Antolín, Defensor del Oyente en el programa "La mañana" (Cadena COPE), para quien la participación de la audiencia representaba una extraordinaria oportunidad para "humanizar la comunicación" y para "conocer la parte del dial que nos oye: me gusta ver a la gente, humaniza la comunicación aséptica. Así no arrojas las noticias contra una tapia sino que luego recibes respuesta" (Antolín, 2000).

\section{PERMITE VALORAR CRÍTICAMENTE A LOS PROFESIONALES DEL PERIODISMO}

Adicionalmente, en determinados casos, la participación de la audiencia en los programas de radio puede servir también como un ejercicio crítico por parte de los oyentes hacia la labor periodística y hacia sus profesionales. Esta posibilidad fue destacada por Favre ya en los años setenta (Favre, 1976: 334) pero adquiere hoy plena actualidad si se tiene en cuenta que, en los últimos años, la mayor parte de las sociedades occidentales ha asistido a la emergencia progresiva de una cultura política crecientemente democrática y participativa. Los mayores niveles de instrucción así como el incremento exponencial del flujo informativo y de los mecanismos de que disponen los consumidores para expresar sus reclamos parecen haber dado lugar a un nuevo consumidor cada vez más exigente. Esta actitud reivindicativa general ha tenido también su reflejo en la exposición mediática de un nuevo consumidor (Diezhandino, 1994: 49-51).

En concreto, el oyente puede valorar críticamente el ejercicio periodístico cuando llama a la radio para rectificar una información o para relatar un caso propio o ajeno que resulte contradictorio con lo expuesto por los contertulios, en el supuesto de una emisión de este tipo. En ambos casos, las intervenciones de los oyentes pueden servir para que los profesionales reflexionen sobre el modo en que afrontan sus tradicionales labores periodísticas (selección y documentación de los temas, grado de conocimiento acerca de ellos, manejo de las fuentes, tratamientos informativos propuestos para la cobertura de los eventos noticiosos, etc.).

Los profesionales consultados mostraron al respecto una cierta discrepancia. Para algunos, "las llamadas de los oyentes son una cura de humildad y una muy sana señal de salud civil" (Burgos, 1992) puesto que -coincidieron en afirmar- "a veces los oyentes están muy preparados y aportan mucho" (Antolín, Rico, Socorro y García, 2000). Por su parte, los partidarios de la postura contraria -menos frecuente que la anterior- sostuvieron que "hay oyentes que hablan muy bien y hay profesionales que hablan muy bien. No es ningún tipo de cura (de humildad)" (Rogado, 2000).

En cualquier caso, una comprensión ponderada de la participación directa de la audiencia debería tener en cuenta que el cierto grado de retroalimentación que permite esta fórmula puede servir de instrumento complementario en el ejercicio de análisis e interpretación de la realidad. Esta ventaja resulta muy útil teniendo en cuenta la deficiente e incompleta aplicación de los mecanismos de autorregulación -orientados a ejercer una valoración crítica de la actividad periodística y de sus profesionales desde un punto de vista deontológico- en la radio española (Herrera, 2002: 
160-180). Aun así, parece más apropiado buscar un adecuado equilibrio entre diferentes mecanismos profesionales para evitar cualquier forma de servilismo de la audiencia, por un lado y la impenetrabilidad de los comentarios de los profesionales, por el otro.

\section{INCREMENTA LOS RECURSOS INFORMATIVOS DE LA EMISORA}

Cuando los oyentes se dirigen a la radio para aportar información, sus mensajes pueden incrementar el número de los recursos técnicos y humanos de los que dispone una emisora para cubrir la actualidad.

La realización más completa de esta ventaja tiene lugar cuando el oyente se dirige al medio para aportar información directa en calidad de testigo y, de una manera muy especial, en la cobertura de la información de sucesos. Los minutos que suceden a la explosión de un artefacto, al comienzo de un incendio, a la realización de un crimen o a la materialización de un accidente suelen ser de extrema confusión. Cuando no se acierta a explicar lo ocurrido y a reconstruir los hechos, la intervención de los oyentes, -ahora testigos de lo visto u oído-, puede ser decisiva para esclarecer algunos aspectos del suceso.

Dado que, en este caso, el oyente se convierte en una fuente más, corresponde a los profesionales confirmar la veracidad de lo relatado, acudiendo para ello a cuantas fuentes oficiales o extraoficiales estimen oportuno. Una vez realizadas estas tareas si, en efecto, la veracidad queda demostrada, las intervenciones de los oyentes pueden servir para reforzar la imagen empresarial de la citada emisora y, por extensión, la credibilidad de la radio en el inmediato seguimiento de la actualidad.

Asimismo, la participación de los oyentes puede proveer de testimonios reveladores en la búsqueda de nuevos datos e informaciones que contribuyan a reconstruir una investigación periodística. Facilitar teléfonos a los que los ciudadanos puedan dirigirse para aportar información se ha convertido en una práctica habitual tanto en la indagación policial como en el periodismo de investigación. Las ventajas de la inmediatez y la instantaneidad propias de la radio vuelven a hacer del medio un cauce privilegiado también para estos fines.

Además, en el caso de que los oyentes se dirijan al medio para relatar un caso propio o ajeno con una intencionalidad interpretativa próxima a la denuncia, su testimonio puede enriquecer el número de puntos de vista de las personas que se encuentran afectadas por una determinada situación. Se consigue así "una respuesta altamente significativa de la alta conciencia de sensibilización en torno a los argumentos y problemáticas que enmarcan a la actualidad" (López, 1996).

En otras ocasiones, los oyentes pueden servir también como fuente de información cuando llaman a la radio para relatar casos propios o ajenos con una intencionalidad menos interpretativa y más descriptiva. Los oyentes pueden ser interpelados para narrar aspectos destacados de su infancia que permitan rescatar ciertos detalles anecdóticos y pintorescos pero, en cualquier caso, 
cercanos a la historia oral y legítima por tanto para reconstruir algunos de los capítulos más desconocidos de nuestra memoria colectiva. Esta es una finalidad de la participación presente, por ejemplo, en el programa "Buenos días" de Radio 1 (RNE). Otras veces, con esta misma intencionalidad descriptiva, los oyentes son interpelados con un reclamo más o menos similar al siguiente: "hoy queremos que los oyentes hagan de Guardia Civil de Tráfico y nos digan cómo está la operación salida y entrada de las grandes ciudades a las playas" ${ }^{\prime \prime}$.

Finalmente, este incremento del número de puntos de vista puede tener lugar también en el interrogatorio de la audiencia. El conocimiento más o menos directo y profundo de la disciplina que se aborde dotará de un mayor dinamismo y variedad a la formulación de las preguntas de la audiencia y facilitará un mayor ajuste entre éstas y las respuestas.

En cualquiera de las variantes mencionadas, el incremento de los recursos técnicos y humanos potencialmente informativos parece ser una de las ventajas en las que los profesionales parecen estar más de acuerdo. Para algunos, "los oyentes son fuentes de información de primera mano, amplían la información que recibes en los periódicos" (Antolín, 2000).

\section{PERMITE ELABORAR TOTAL O PARCIALMENTE EL PROGRAMA}

El hecho de que los oyentes se dirijan a un programa puede significar también una ventaja desde el punto de vista del abaratamiento de costes para su producción. En comparación con el empleo de otros recursos (establecimiento de conexiones con corresponsales en el extranjero, realización de reportajes, elaboración de tertulias, etc.) la participación directa de la audiencia permite llenar un tiempo de emisión con escasos costes ya que, muchas veces, son los propios oyentes quienes afrontan el gasto de las llamadas.

Lógicamente, esta ventaja se encuentra condicionada por la presencia que tenga esta fórmula en el contenido global de la emisión y resulta por tanto evidente en la participación esencial, que configura programas y secciones basados exclusivamente en esta fórmula, de tal modo que, sin ella, el programa o la sección pierde su razón de ser (Merayo, 2000: 219). Esta modalidad de participación se encuentra hoy muy presente en la actual programación radiofónica de madrugada.

De hecho, conviene recordar que el nacimiento de esta programación se situó en 1979, año en el que las emisoras radiofónicas eliminaron definitivamente la pausa nocturna que tenía lugar entre las dos o las tres de la madrugada y las seis de la mañana. El paso hacia una programación ininterrumpida durante las 24 horas del día llevó a considerar, en un primer momento, la participación directa de la audiencia como una fórmula apropiada con la que rellenar, sin grandes costes de producción adicionales y sin necesidad de una exhaustiva labor de preparación previa, el "hueco" que se producía a estas horas de la madrugada (Balsebre, 1999: 159).

${ }_{4}$ Del Olmo, Luis, escuchado en "Protagonistas", en la emisión de 30 de julio de 2001. 
Desde entonces, la popularidad que han ganado estas emisiones ha llevado a algunos críticos a afirmar que recurrir a la participación de la audiencia es un modo barato con el que justificar la falta de elaboración del programa. Sin embargo, tampoco han faltado voces críticas a esta afirmación por parte de los profesionales. Una de las más significativas fue la de Pilar Socorro, quien señaló que: "Para hacer un programa bien hecho, atractivo, hay que trabajarlo mucho. Saber moderar, cortar o dar cancha a lo oyentes. No es nada barato, es muy difícil manejar a los oyentes que a veces están más preparados que tú" (Socorro, 2000).

La consideración ponderada de la participación directa de la audiencia que aquí se presenta asume que, en efecto, se trata de una fórmula relativamente barata para realizar un programa. No obstante, su empleo no debería involucrar una simplificación en exceso del ejercicio profesional $y$, en ningún caso, debería suponer una abdicación por parte del conductor del espacio en el desempeño de su labor periodística. Al fin y al cabo, los oyentes no dejan de ser sino un elemento más en el programa y se precisa de una mediación profesional que, desde un conocimiento profundo de la audiencia a la que se dirige, sepa identificar los temas que más puedan interesar y estructurar la conversación.

\section{ACERCA EL MEDIO AL PÚBLICO}

Para algunos autores, la participación directa de los oyentes en los programas de radio fue una de las principales reivindicaciones de las denominadas emisoras libres y comunitarias, surgidas originariamente en los años sesenta y reinventadas posteriormente, con el objeto de dinamizar la producción radiofónica a partir de su consideración como medios interactivos vinculados al espíritu de lucha para la liberación de las ondas (Kaplun, 1978: 73, Ibarra, 1990 y Lewis y Booth, 1992: 175-176). Se trataba de reclamar una manera distinta -más descentralizada y popularizada- de concebir la radio que precisaba necesariamente de las intervenciones de los oyentes.

También en la radio generalista de ámbito nacional, la participación directa de los oyentes en sus programas puede, en efecto, acercar el medio a los ciudadanos al permitirles tomar parte en sus contenidos. De esta forma, el hecho de que los oyentes puedan participar en los discursos puede hacer comprender -a los que participan y a los que no- el funcionamiento de la radio como medio de comunicación, así como sus condiciones de producción y emisión. Además, Simonelli y Taggi han señalado que "se telefonea a la radio (...) para saber, para aclarar las propias dudas sobre materias que una transmisión cualquiera no podrá revelarnos sino por acercamientos aproximativos" (Simonelli y Taggi, 1985: 143).

Así, esta fórmula "reafirma una imagen empresarial de emisora pluralista, abierta a las opiniones de los ciudadanos, lo que siempre revierte en credibilidad y en la consecución de un mayor número de oyentes" (Merayo, 2000: 217). Esta constatación no ha pasado desapercibida para los publicistas del medio, que han utilizado esta posibilidad como reclamo publicitario. Además, en la actualidad, el incremento de la competencia ha obligado a redoblar los esfuerzos en la búsqueda 
de frases promocionales que atraigan a la audiencia. Este es el caso de slogans como "Cada día más cerca de ti", (RNE, 2000/2001) "La radio que te escucha" (Onda Cero, 1999/2000) o "La principal estrella eres tú" ("Cita con Pilar", Radio 1, 1999).

El deseo de programadores y productores ha sido bien entendido por parte de los oyentes, hasta el punto de que, en ocasiones, esa cierta sensación de que la radio les pertenece puede llegar a convertirse en una de las principales motivaciones por las que los oyentes pueden decidirse a llamar a una emisora.

Una variante de este acercamiento con el medio puede tener lugar cuando un programa determinado permite a los oyentes que se pongan en contacto con un profesional que, en ese momento, asiste como invitado a la emisión. En el interrogatorio de la audiencia, algunas intervenciones van precedidas por afirmaciones del tipo: "Antes de nada, enhorabuena por el programa porque la verdad es que me hacéis pasar momentos muy divertidos y además, hoy me permite saludar y felicitar a XXX, a quien siempre he admirado mucho. He leído todos sus libros/visto todas sus películas/comprado todos sus discos y lo cierto es que...". Además, el empleo de la participación directa de la audiencia en la realización de entrevistas de personalidad y en profundidad puede aportar aspectos interesantes y anecdóticos derivados, por ejemplo, de la actividad profesional del oyente. Estas intervenciones permiten conocer elementos de carácter humano que pueden resultar de gran interés para el desarrollo de la emisión (Merayo, 2000: 222).

Con independencia de la lectura más o menos promocional que pueda extraerse de esta ventaja, esta fórmula permite reforzar el acercamiento del público al medio y pone en contacto a personas que, tal vez, de otra manera nunca llegarían a encontrarse.

\section{LA EMISIÓN RESULTA MÁS DINÁMICA}

Por la misma naturaleza de la radio, las modalidades de participación en directo resultan, en principio, más propias y ajustadas al medio que las modalidades en diferido. Con una condición: que se garantice la competencia comunicativa del oyente. No se trata de invalidar aquí otras formas de participación que puedan tener lugar en diferido (a través de las cartas, del chat, del correo electrónico o del resumen realizado por el portavoz o defensor del oyente). Éstas y otras modalidades que puedan aparecer en el futuro son, en términos informativos, igual de eficaces que las que tienen lugar a través de la incorporación en antena de la voz del oyente.

Es en el aspecto esencialmente comunicativo donde la participación en directo de la audiencia puede proporcionar un "suplemento de vida" (Duhamel, 1976: 53), dando lugar a testimonios ilustrativos, vibrantes y dotados de una gran fuerza expresiva (McLeish, 1985: 182). Además, estas modalidades se ajustan a un momento de la narrativa radiofónica en el que se busca más la in- 
tensidad comunicativa. Frente a otros periodos en los que los modos de contar exigían de los profesionales unas determinadas cualidades fonogénicas, hoy se observa un cambio de estilo en esta tendencia (Cebrián Herreros, 1994: 401).

La intervención directa de los oyentes está enmarcada en un discurso caracterizado en lo lingüístico por ser dialógico, conversacional y coloquial, un discurso que permite establecer una mayor proximidad psicológica con el resto de la audiencia. Esta cualidad ha sido percibida por los profesionales del medio. Para Luis Del Olmo, por ejemplo, "el teléfono ha permitido a los oyentes dejar de ser orejas pasivas, convirtiéndoles en programadores". La radio dispone de unas notas diferenciales que privilegian la participación directa de la audiencia (Herrera, 2003: 25-40), frente a lo que se observa en otros medios como la prensa o la televisión. Además, por la mayor amplitud de registros del lenguaje oral frente al escrito, incluir en antena las voces de los oyentes puede aportar nuevas connotaciones semánticas y un mayor dinamismo estético a la emisión. Esta ventaja puede resultar también de especial interés cuando los oyentes llaman a la emisora para relatar un caso propio o ajeno o para formular una denuncia.

\section{INCONVENIENTES DE LA PARTICIPACIÓN DIRECTA DE LA AUDIENCIA}

Sin embargo, junto a las ventajas descritas, el empleo de la participación directa de la audiencia entraña también una serie de inconvenientes. Al posibilitar una mediación profesional ejercida sólo en la última etapa del proceso comunicativo, la inclusión en antena de las voces de los oyentes facilita un contacto sólo provisional, efímero, no sistemático y no estructurado entre profesionales y audiencia, lo cual origina ciertos inconvenientes. En ciertos casos, el contenido de la objeción considerada resulta ser el anverso de lo que antes se describió como una ventaja. He aquí una impresión preliminar: en virtud de su carácter instrumental, la participación directa de los oyentes es una fórmula puesta a disposición del medio y de su audiencia. De su utilización -más o menos acertada- dependerá en gran medida su contribución al programa en el que se encuentra inserta.

\section{SE MULTIPLICA LA ANARQUÍA INFORMATIVA}

Una radio en la que se advierta un excesivo acceso podría dar lugar a cierta publicidad para grupos irrelevantes de la sociedad, incrementando así el ruido informativo. Precisamente esta fue una de las formulaciones más críticas contra la radios libres (Prado, 1983: 111, Ibarra, 1991, Guattari, 1981: 233, Eco, 1981: 227 y ss.).

En la actualidad, como consecuencia de la normalización de la vida política y del aumento del número de actores que operan en el panorama radiofónico español, este inconveniente ha reducido en cierto modo sus efectos. Aun así, se trata de una posible limitación de la participación de la audiencia que hoy presenta otras variantes.

Una de ellas se refiere a la posibilidad de que las intervenciones de los oyentes supongan determinadas formas de injuria o insulto, una posibilidad incrementada por el hecho mis- 
mo de que cualquier oyente pueda ampararse cómodamente -y a veces de manera cobardetras el anonimato. Este inconveniente también fue destacado por algunos profesionales. Manuel Antonio Rico consideró que otro posible riesgo es que las intervenciones "se alarguen demasiado" y que "se salgan del tono del programa". A juicio de Elguero, uno de los principales riesgos consiste en "hacer daño: herir a los colectivos" (Elguero, 2000). Otras veces, es posible que los consejos inexpertos que se ofrezcan desde el estudio molesten a aquellos oyentes que saben más del tema y resulten perjudiciales para el oyente y para el resto de la audiencia (McLeish, 1985: 138).

Además, sin una mediación profesional apropiada y capaz de dirigir la conversación de manera ordenada, la participación de la audiencia podría terminar devorándose a sí misma sin llegar a aportar conclusiones interesantes y novedosas para el debate. La sucesión de opiniones que se anulan unas a otras en el curso de un proceso accesible pero caótico es la materialización más gráfica de lo que se quiere expresar. El programa quedaría así convertido en una mera yuxtaposición de opiniones encontradas en las que el peso de cada intervención quedaría anulado por el peso de la intervención que le sucediera inmediatamente después.

Es cierto que la evolución experimentada por la participación directa de la audiencia ha rutinizado ciertas prácticas profesionales destinadas precisamente a minimizar este riesgo. Una de las más empleadas consiste en la filtración de llamadas por parte del productor, quien mantiene una breve entrevista con el oyente para conocer su identidad y procedencia así como el tema sobre el que desea intervenir. Sin embargo, lo cierto es que esta práctica no resuelve en todos los casos el posible inconveniente de la multiplicación de la anarquía informativa. Como se ha apuntado en alguna ocasión, la disyuntiva podría quedar más o menos resumida en los siguientes términos: "Si la selección es demasiado prudente, uno de los objetivos principales a que apela la participación (ampliar la gama de puntos de vista propuestos al público) no se realizará, y el organismo en cuestión se verá acusado de echar mano de la censura; si la elección es demasiado aventurada, los grupos pueden llegar a comportarse o expresarse de manera tan intolerable para cierto público que la empresa se encontrará comprometida: tacharán al organismo de parcialidad, de irresponsabilidad e incluso de infracción de las leyes" (Favre, 1976: 346).

Además, los oyentes pueden desconocer el tema, dando lugar a intervenciones poco solventes o desordenadamente expuestas. Se trata de un riesgo inevitable que ninguna emisora, profesional o programa debería subestimar.

\section{SE PUEDE UTILIZAR LA FÓRMULA DE MANERA TENDENCIOSA}

También ha sido un riesgo advertido por los primeros estudiosos de este fenómeno. La incorporación de las llamadas telefónicas expresa la creencia actual de la espontaneidad y pone de manifiesto una cierta reacción contra el formalismo. Sin embargo, esta posibilidad puede presentar un aspecto negativo si la fórmula se utiliza para otros fines. 
Así, por ejemplo, podría darse el caso de que los profesionales utilizaran la fuerza y el impacto expresivo de las intervenciones seleccionando sólo aquellas que resultasen proclives y favorables a la línea editorial de la emisora y a sus intereses. De esta forma, la participación directa de la audiencia quedaría convertida en un elemento barato para hacer radio de opinión. Esta posibilidad ha sido criticada por algunos profesionales del medio en España. Iñaki Gabilondo ha destacado el riesgo que podría producirse ante la presencia frecuente de una serie de "oyentes habituales" en los espacios para la participación directa de la audiencia: "No me gusta que se encargue el programa a esa especie de demagógica operación que consiste en que hablen los oyentes. A mí me parece que los oyentes pueden y deben constituir una especie de referencia, de rebote, de contacto, pero no un brindis al sol. Si usted tiene una cita con los oyentes siempre a la misma hora corre el riesgo de que los habituales de la llamada se apoderen de la antena" (Balsebre, 1999: 148).

Desde esta perspectiva, Cebrián Herreros ha destacado también que la utilización excesiva de esta fórmula en la actual programación ha hecho que, en realidad, lo que fue un hallazgo en su momento "se esté volviendo ahora contra ella" (Cebrián Herreros, 1994: 144).

\section{SE PUEDE UTILIZAR LA FÓRMULA DE MANERA MERAMENTE COMERCIAL}

Además, dado el abaratamiento de costes que supone esta fórmula también cabe la posibilidad de que su uso responda sólo a intereses comerciales y no a las finalidades antes expuestas. Así lo destacaron algunos profesionales del medio con cargos ejecutivos. Para Francisco Fernández Oria, Director de Programas y Emisiones de RNE, recurrir a la participación directa de la audiencia, "abarata la radio y llena tiempo". Por su parte, el Director de Análisis de Contenido de RNE, Félix Gallardo, afirmó también que se trataba de "un recurso que se utiliza para todo sin pensárselo". María José Bosch, directora y presentadora del programa "La noche" (Cadena COPE) señaló a este respecto: "parece un poco peyorativo pero estoy de acuerdo". Matías Antolín, Defensor del Oyente en "La mañana", de la misma cadena, afirmó: "Puede que sí, lo más barato. De esa forma, los oyentes te hacen el programa. Es lo más barato, lo más fácil, lo más cómodo y tiene interés porque aparecen voces nuevas, porque los programas siempre los dirigen los mismos y estos cogen mucho protagonismo".

También quienes han analizado esta fórmula en la radio de otros países han advertido este inconveniente. Además del posible sesgo y parcialidad en la selección de las intervenciones, la participación directa de la audiencia mantiene así una estrecha relación con ciertos aspectos comerciales. Para Duhamel, "en los programas de participación se está considerando al oyente más como un animador que como un verdadero participante" (Duhamel, 1976: 53). Las afirmaciones del autor se refieren a una radiodifusión algo pretérita y en los últimos años estos programas han experimentado una gran variedad de innovaciones. Aun así, sus palabras siguen teniendo plena actualidad a juzgar por la escucha del empleo de esta fórmula en diferentes modelos de programación radiofónica, como el de la radiofórmula. 
Más recientemente, en referencia a la radio mexicana, Winocur ha criticado, por ejemplo, la paradoja que tiene lugar cuando se constata que la construcción de legitimidad intrínseca de esta fórmula se ha vuelto eficiente sólo en términos comerciales. Por el contrario, esta construcción de legitimidad ha resultado ineficiente en la lógica pública donde, por el contrario, presentar a la radio como "servicio al público" se ha convertido más bien en una limitación, toda vez que las demandas de los públicos se han hecho cada vez más volubles y fragmentadas (Winocur, 2000: 44).

\section{LAS INTERVENCIONES PUEDEN RESULTAR DEMASIADO PARTICULARES}

En algunas modalidades participativas, la singularidad de la intervenciones se presenta no sólo como algo deseable sino que, de hecho, constituye la razón de ser y la principal justificación de aquéllas. Así se advierte, por ejemplo, en las modalidades de relato de un caso propio o ajeno o en la mayor parte de las intervenciones que tienen por objeto formular una consulta. En ambos casos, los oyentes son interpelados para que se dirijan al medio y expongan sus vivencias o para que argumenten sus particulares puntos de vista a propósito de un tema más o menos polémico- que en ese momento se encuentre presente en la agenda mediática.

Sin embargo, en otros casos, esta misma ventaja conlleva a su vez el riesgo de que las intervenciones resulten demasiado particulares y por tanto carezcan de interés para el común de la audiencia (Cebrián Herreros, 1994: 144). Este inconveniente se agrava además si va unido a una cierta incompetencia comunicativa por parte del oyente al tender, por ejemplo, a una exposición demasiado extensa de su problema o de su punto de vista o al expresar una actitud demasiado vehemente a la hora de defender sus argumentos

\section{SE PUEDE IDENTIFICAR FALSAMENTE LA OPINIÓN PÚBLICA CON LA OPINIÓN DEL PÚBLICO}

La falta de representatividad ha sido también uno de los aspectos más criticados de los programas que incorporan la participación de los oyentes. Para Magnus, no se puede hablar en modo alguno de representatividad cuando los oyentes se dirigen de manera espontánea a la redacción para aportar sus puntos de vista (Magnus, 1976: 370). Tampoco se puede hablar de representatividad si los oyentes han sido invitados por el equipo de producción de la emisora para participar en un debate o discusión: "Trabajar con tales grupos 'arrepresentativos' es invocar el peligro latente de dar imágenes falaces e informaciones erróneas sobre los oyentes, tanto a los responsables del programa como al gran público (...). Por el camino de estos grupos no representativos se puede llegar a una idea errónea de las tendencias y de las relaciones de la mayoría dentro del seno del público, lo que, a su vez, puede conducir a una self fulfilling prophecy" (Magnus, 1976: 326).

En ocasiones, se ha recordado también que la utilización de encuestas callejeras o de líneas abiertas puede originar la falacia de querer interpretar al conjunto de los ciudadanos a 
través de la opinión de unos cuantos, generalizando así el engaño de identificar la opinión pública con la opinión del público (Sampedro, 2000: 180-184). Esta falsedad también fue destacada por los profesionales encuestados que subrayaron que era imposible identificar el perfil de la gente que llama con el resto de la audiencia. Elguero, por ejemplo, afirmó que "el perfil de la gente que llama no es el mismo que el del público global". En similares términos se expresó José María Pascual (Elguero y Pascual, 2000).

Desde un punto de vista estrictamente numérico, es evidente que esta fórmula presenta numerosos problemas en cuanto a la representatividad de las intervenciones y en lo relativo también a la posibilidad de extrapolar éstas al sentir común de la audiencia-mucho menos de la sociedad-. La definición ponderada de la participación que se trata de sostener aquí es consciente de que, siendo este un problema evidente, no resulta tan grave si se entiende que no es la de representar a la opinión pública la finalidad que se persigue o que se debería perseguir con esta fórmula. Se trata más bien de defender su utilización moderada como herramienta válida para sondear en cierta medida algunas de las opiniones de algunos de los sectores de la población con respecto a algunos de los problemas o de las situaciones socio-políticas.

Por lo demás, es obvio que la medición de la opinión pública como tal resulta una función demasiado ambiciosa para esta fórmula, habida cuenta de que ello presentaría adicionalmente innumerables problemas de tiempo, dinero y recursos. Sin embargo, reconocer esta realidad no invalida su potencialidad para obtener un cierto grado de respuesta del público respecto a los temas que se aborden en el programa y como fuente adicional de posible conocimiento del público: de sus intereses, de sus necesidades, de sus opiniones y de sus preferencias.

\section{SE PUEDEN PRODUCIR FALSIFICACIONES, ENGAÑOS, EXAGERACIONES O DISTORSIONES}

Algunos críticos han añadido además que el empleo de la participación directa de los oyentes en los programas de radio es susceptible de producir las mismas falsificaciones, engaños, exageraciones o distorsiones que caracterizan el intercambio verbal entre personas. En muchos casos, las intervenciones de los oyentes suelen surgir desde la improvisación, una realidad no exenta de problemas: "Quien improvisa se inclina a la parcialidad y a la exageración, a la prolijidad y a la divagación cuando deja fluir sus ideas. Si la radio quisiera utilizar la improvisación como norma para la transmisión de acontecimientos, la calidad media del programa se vería muy mermada, tanto desde el punto de vista del contenido como de la forma" (Arnheim, 1980: 131).

Una variante de este inconveniente puede encontrarse en el sesgo derivado de la intervención habitual en el programa de una serie de amigos o enemigos -según los casos- del conductor o del invitado del programa. Tampoco esta posibilidad ha pasado desapercibida para quienes han estudiado esta fórmula participativa en otros medios. Con respecto a la sección 
"Cartas al director", se ha afirmado que el carácter de servicio público de este espacio no puede ser confundido con su utilización parcial e interesada en aras del beneficio económico o ideológico del diario. Sin embargo, la práctica habitual ha hecho que actualmente "pueda afirmarse sin empacho que la sección de cartas de los lectores, sabiamente manejada, se convierte en un arma de reconocida eficacia al servicio de la línea editorial del medio" (Morán, 1988: 225-226).

En la radio, la posibilidad de que los oyentes generen distorsiones y orienten el programa en una sola dirección puede verse incrementada si los partidarios o detractores de una personalidad política, sindical o de otro tipo deciden aprovechar su presencia en el programa para formular sus aplausos o críticas, según los casos (Cebrián Herreros, 1992: 353). Lógicamente, considerada de esta forma, la participación se convierte en un contrasentido porque se reduce considerablemente la posibilidad de escuchar a otras personas y porque, en algunos casos, este riesgo puede entrañar consecuencias negativas en la alteración del orden público ${ }^{5}$. Sin llegar a estos extremos, es necesario tener en cuenta que, en ocasiones, el principal motivo por el que los oyentes exageran algunos aspectos de sus historias se debe a un cierto afán de protagonismo o a la posibilidad de que se tomen ciertas licencias retóricas a la hora de narrar sus experiencias. Estos inconvenientes pueden ser reforzados como consecuencia del anonimato que ofrece la radio. En cualquier caso, se trata de una disfuncionalidad que los profesionales del medio han de contemplar con cierta prudencia.

\section{CONCLUSIÓN}

En síntesis, la existencia de estos aspectos positivos y negativos pone de manifiesto no sólo el carácter instrumental de la participación directa de los oyentes en los programas de radio, sino también su posible correcta o incorrecta utilización. Aunque, en términos generales, las ventajas son mayores que los inconvenientes, el efecto de estos últimos es considerable y no debería ser despreciado por los programadores del medio antes de proceder a su inclusión. Además, teniendo en cuenta que la mayor parte de los riesgos se derivan de que la mediación profesional tiene lugar sólo en la última etapa del proceso comunicativo, merece la pena insistir en la importancia de esta mediación, no sólo al final del proceso sino -preferentemente- en la misma configuración y diseño de las programaciones y emisiones.

\footnotetext{
${ }^{5}$ En junio de 1994, por ejemplo, la policía autonómica catalana detuvo a un oyente del programa "Hablar por hablar" por presunta corrupción de menores. El oyente dijo en antena que había tenido relaciones sexuales con niñas de 12 a 14 años de edad. Posteriormente, fue puesto en libertad cuando se comprobó en la confesión policial que el contenido de su intervención en la emisión radiofónica había sido producto de su imaginación. Cfr. Balsebre, 1999: 162.
} 


\section{REFERENCIAS BIBLIOGRÁFICAS}

- Arnheim, R. (1980): Estética radiofónica, Barcelona: Gustavo Gili.

- Balsebre, A. (coord.) (1999): En el aire. 75 años de radio en España, Madrid: Promotora General de Revistas.

- Burgos, A. (1992): Diario 16, 13 de octubre de 1992.

- Cebrián Herreros, M. (1992): Géneros informativos audiovisuales. Radio, televisión, periodismo gráfico, cine y vídeo, Madrid: Ciencia 3.

- Cebrián Herreros, M. (1994): Información radiofónica. Mediación técnica, tratamiento y programación, Madrid: Síntesis.

- Diezhandino, P. (1994): Periodismo de servicio. La utilidad como complemento informativo en Time, Newsweek, US News y World Report y unos apuntes del caso español, Barcelona: Bosch.

- Duhamel, S. (1976): "La radio sus oyentes y los poderes públicos", en Madrid: Reencontres de Tenerife, pp. 49-53.

- Eco, U. (1981): "Una nueva era en la libertad de expresión", en Bassets, LI. (ed.): De las ondas rojas a las radios libres, Barcelona: Gustavo Gili, pp. 213-230.

- Favre, D. (1976): "La participación directa de los oyentes en los programas de radio", en Madrid: Reencontres de Tenerife, pp. 332-354

- Guattari, F. (1981): "Las radios libres populares", en Bassets, LI. (ed.), De las ondas rojas a las radios libres, Barcelona: Gustavo Gili, pp. 231-236.

- Herrera, S. (2002): La participación de la audiencia en la radio española: evolución, evaluación e implicaciones para la práctica profesional. Estudio del caso de RNE Radio 1 (1999/2000), Tesis doctoral, Pamplona: Universidad de Navarra.

- Herrera, S. (2003): "Rasgos diferenciales de la radio como medio de participación", Revista de Comunicación, vol. I, pp. $25-40$.

- Ibarra, E. (1990): "Radios comunitarias", Márgenes, núm. 3.

- Ibarra, E. (1991): "Aproximación a la radio comunitaria. Una estrategia para democratizar la palabra", Voces y culturas, núms. 2-3.

- Kaplun, M. (1978): Producción de programas de radio: el guión, la realización, Quito: Ciespal.

- Keane, J. (1997): "Transformaciones estructurales de la esfera pública", Estudios Sociológicos, vol. XV, núm. 43.

- Lalinde, A.M. (1998): "Radio informativa, ¿es posible la participación?", Signo y pensamiento, núm. 33, pp. 47-58.

- Lewis, P. y Booth, J. (1992): El medio invisible: radio pública, privada, comercial y comunitaria, Barcelona: Paidós.

- López, P. (1996): Los magazines de la radio española: modelos, tendencias y representación de género, Tesis doctoral, Madrid: Universidad Complutense de Madrid.

- Magnus, U. (1976): "Participación directa del oyente en el programa radiofónico", en Madrid: Reencontres de Tenerife, pp. $321-331$. 
- McLeish, R. (1985): Técnicas de creación y realización en radio, Madrid: Instituto Oficial de Radio y Televisión.

- Merayo, A. (2000): Para entender la radio, Salamanca: Publicaciones Universidad Pontificia de Salamanca, $2^{a}$ edición.

- Morán, E. (1998): Géneros del periodismo de opinión: crítica, comentario, columna, editorial, Pamplona: Eunsa.

- Muñoz, J.J. y Gil, C. (1986): La radio: teoría y práctica, Madrid: Instituto Oficial de Radio y Televisión.

- Nierga, G. (1996): Hablar por hablar, Barcelona: Planeta.

- Norberg, E. (1998): Programación radiofónica: estrategia y tácticas, Madrid: Instituto Oficial de Radio y Televisión.

- Prado, E. (1983): Las radios libres, Barcelona: Mitre.

- Sampedro, V. (2000): Opinión pública y democracia deliberativa. Medios, sondeos y urnas, Madrid: Istmo.

- Simonelli, G. y Taggi, P. (1985): Il fantasmi del dialogo, Roma: Bulzoni Editori.

- Winocur, R. (2000): "La participación en la radio: una posibilidad negociada de ampliación del espacio público", Diálogos de la Comunicación, núm. 58, pp. 37-46.

\section{ENTREVISTAS CON PROFESIONALES:}

Antolín, M. (2000): en conversación personal con la autora Elguero, I. (2000): en conversación personal con la autora García, J.A. (2000): en conversación personal con la autora Nierga, G. (2000): en conversación personal con la autora Pascual, J.M. (2000): en conversación personal con la autora Rico, M.A. (2000): en conversación personal con la autora Rogado, B. (2000): en conversación personal con la autora Socorro, P. (2000): en conversación personal con la autora 